\title{
Prevalence and Characteristic of Dietary Supplement Users in Malaysia: Data From the Malaysian Adult Nutrition Survey (MANS) 2014
}

\author{
Nor Azian Mohd Zaki ${ }^{1}$, Mohd Naim Rasidi ${ }^{1,2}$, S Maria Awaluddin', Tee Guat Hiong1, \\ Hasimah Ismail ${ }^{1} \&$ Noor Safiza Mohamad Nor ${ }^{1}$ \\ ${ }^{1}$ Institute for Public Health, Kuala Lumpur, Malaysia \\ ${ }^{2}$ Penang General Hospital, Penang, Malaysia \\ Correspondence: Nor Azian Mohd Zaki, Institute for Public Health, Ministry of Health, Jalan Bangsar, 50590, \\ Bangsar, Kuala Lumpur, Malaysia. Tel: 603-22-979-400.E-mail: adzian_81@yahoo.com
}

Received: June 27, 2018 Accepted: November 6, 2018 Online Published: November 27, 2018

doi:10.5539/gjhs.v10n12p127 URL: https://doi.org/10.5539/gjhs.v10n12p127

\begin{abstract}
Background: There has been an increase trend of dietary supplements intake among Malaysians over the last decade. The aim of this study was to determine the prevalence and characteristic of dietary supplements users among adults in Malaysia.
\end{abstract}

Methods: Data of 3000 respondents aged 18-59 years from the Malaysian Adult Nutrition Survey (MANS) 2014 were utilized. A multi-stage stratified sampling method was employed and eligible respondent from each household was selected using Kish method. Validated questionnaire was used to gather information on vitamin/mineral supplements (VMS) and food supplements (FS). Descriptive analysis and multiple logistic regressions were conducted using SPSS version 20.0.

Results: The prevalence of VMS and FS intakes among adults in Malaysian were $28.1 \%$ and $34.0 \%$ respectively. Women, older aged adults with higher education level and monthly income were more likely to consume dietary supplements. Vitamin C and multivitamin/ multimineral, were the commonest VMS consumed by the respondents. The most common FS taken were fish oil and royal jelly. The main causes for dietary supplements intake include for health reasons, doctor's prescription, to increase energy level and for beauty.

Conclusions: About one third of the Malaysian adults took variety of dietary supplements. Thus, information based on the scientific evidences of health benefits for each type of the dietary supplements is needed to enable consumers to make informed choices on the dietary supplements.

Keywords: Dietary supplement, Vitamin and mineral supplement, Food supplement, Malaysian survey

\section{Introduction}

Over the last decade, the dietary supplement consumption in the population has been increased, particularly in the United States (US) (Gahche et al., 2011; Wu et al., 2011). The Dietary Supplement Health and Education Act (1994) defines a dietary supplement as a "product intended to supplement the diet that contains one or more of the dietary ingredients; vitamin, a mineral, an herb or other botanical compounds, an amino acid, or a dietary substance to supplement the diet by increasing the total dietary intake" (National Institutes of Health, 1994.). The varieties and numbers of dietary supplement have increased tremendously due to the growing interest to maintain health and to prevent disease among consumers (Bailey et al., 2013).

Recommendation or prescription of dietary supplements from health professionals to their clients to promote health may increase the prevalence of dietary supplement use (Dickinson et al., 2012). Demand on dietary supplement use had also increased among individuals who seek alternatives to drugs prescription or as a nutritional enhancement. In addition, the vast amount of advertisements in mass media on the benefit of dietary supplements and recommendations from families or friends may influence the consumption of the dietary supplements (Goston and Correia, 2010). There was evidence suggesting combination of nutrients in some supplements may be helpful to reduce incidence of chronic disease among at-risk populations such as cardiovascular disease (CVD) and cancer (Comerford, 2013). However, high doses of supplements could be harmful and may be ineffective for preventing mortality and morbidity related to chronic disease (Guallar et al., 2013). 
According to the National Health and Nutrition Examination Survey (NHANES) 2003-2006, about 50\% of the adult population in the United States of America used dietary supplements with one third consumed multivitamin and multimineral supplements (Bailey et al., 2011). In European countries, the dietary supplement intake prevalence was found higher in Northern countries than in Southern Europe (Skeie et al., 2009). Meanwhile, the prevalence of dietary supplement used was reported in South Korea was much higher than other countries which is about $60 \%$ (Ock et al., 2010). In Malaysia, the first national nutrition survey on representative sample of the population in 2003 has reported that about $25 \%$ of the adults took dietary supplement (Ministry of Health Malaysia, 2008).

Malaysia has undergone rapid urbanization resulting in rapid changes of dietary intakes including the dietary supplements intakes. Evidence from epidemiological studies have suggested that there was a positive association of dietary supplement used among women, adults with higher level of education and those who are relatively wealthy (Pouchieu et al., 2013; Xiaoyan et al., 2009). However, information related to the associations between dietary supplement and socio demographic or lifestyle factors in Malaysia are still lacking. Therefore, the present study aimed to determine the prevalence of dietary supplements use and its association with socio demographic and lifestyle factors among the Malaysian adults, using nationally representative data from the Malaysian Adults Nutrition Survey (MANS) 2014. The findings of this study will hopefully support the evidence-based food and nutrition policies, intervention studies and education program related to dietary supplements in Malaysia.

\section{Methods}

\subsection{Data Source}

Malaysian Adults Nutrition Survey (MANS) was a nationwide population-based, cross-sectional survey conducted in 2014. The population was stratified into urban rural residency covering Peninsular Malaysia, Sabah and Sarawak. The respondents were selected using multi-stage cluster sampling design. Data on nutrition intakes of Malaysian population including dietary supplements were collected using face to-face interviews from March to June 2014. The total number of households sampled was 4044 and one eligible adult aged 18 to 59 years was chosen from each household using Kish table to participate in the survey. Pregnant mothers and participants with critical illness were excluded from this study. The number of respondents who took part in this survey was 3000 . The number of respondents who answered questions on vitamin and mineral supplements was 2991 (99.7\%) and respondents who answered questions on food supplements were 2999 (99.8\%). Detailed descriptions of the survey design, sample and procedure are available elsewhere (Institute for Public Health (IPH), 2014). Written informed consents were obtained from all participants or their proxies and ethical approval was obtained prior to the survey from the Medical Research and Ethics Committee, Ministry of Health, Malaysia (NMMR-12-815-13100).

\subsection{Instruments}

Structured questionnaires were used to collect information from the respondents by trained Nutritionist. In this study, dietary supplements were categorized into two categories, i.e, vitamin and mineral supplements (VMS) and food supplements (FS). VMS were defined as mineral, synthetic nutrients and vitamin sold singly or in combination such as multivitamin, vitamin C, iron and others. FS supplements were defined as product with health claim that made from natural food or food derivatives, for example bee pollen, spirulina, traditional herbs and others. Participants were asked whether they had taken any supplements in the past 12 month. Participants were also asked about the type of supplements use and reasons for using. If respondents were not sure on the type of supplements, they were asked to show the packaging or labels of the supplements.

Selected characteristics were considered as covariates in the analysis that might be associated with the dietary supplements. Socio-demographic characteristic included locality (urban versus rural), gender (male versus female), age groups (18-29 years, 30-39 years, 40-49 years and 50-59 years), ethnicity [Malay, Chinese, Indian, Other Bumiputera (Malaysian ethnics from Sabah and Sarawak excluding Malay, Chinese and Indian)] and Others [non Malaysian citizens)], highest education level (no formal education, primary, secondary and tertiary), household monthly income (less than RM1500, RM1500-3500 and more than RM3500).

Lifestyle factors included body mass index (BMI) i.e. underweight, normal, overweight and obesity. Anthropometry measurement was performed using validated and calibrated tools. A digital weighing machine (Tanita Personal Scale HD 319) was used to measured weight of respondents, and height was measured using SECA Stadiometer 217. Body mass index (BMI) was categorized according to the WHO guidelines (World Health Organization [WHO], 2000) as underweight (BMI $<18.5 \mathrm{~kg} / \mathrm{m}^{2}$ ), normal weight (BMI 18.5-24.9 kg/m²), overweight (BMI 25.0-29.9 kg/m ${ }^{2}$ ) or obese (BMI $\geq 30.0 \mathrm{~kg} / \mathrm{m}^{2}$ ). (WHO, 2000) Data on physical activity was collected using International Physical Activity Questionnaire (IPAQ) short form. Participants with physical 
activity levels of less than 600 MET minutes/ week were considered inactive (WHO, 2004).

\subsection{Statistical Analysis}

Data analyses were conducted using SPSS version 20.0. The prevalence of dietary supplements use among the Malaysian adults was analyzed using descriptive analysis. Chi Square test was used to determine the differences between groups. The effect of socio-demographic profiles (location, gender, age, ethnicity, education level and monthly income), body weight and physical activity status were evaluated using univariable and multivariable logistic regression. For any potential predictor variable, effect size was estimated by crude (univariable logistic regression) and adjusted (multivariable logistic regression) odds ratios with $95 \%$ confidence intervals. Statistical significance was set at $\mathrm{p}$ value $<0.05$.

\section{Results}

A total of 3,000 Malaysian adults were involved in this study. The findings from our study showed that $28.1 \%$ and $34.0 \%$ of the respondents in our study had taken any VMS and FS, respectively, during the past 12 month. A higher prevalence of dietary supplement was reported among women than men, i.e, $32.1 \%$ vs. $24.3 \%$ for VMS ( $<<0.001)$ and $38.4 \%$ vs. $30.0 \%$ for FS ( $<<0.001$ ). The prevalence of VMS users was highest among adults ages 30-39 years old, while FS users was highest among adults aged 50-59 years old. By ethnicity, Chinese had the highest prevalence of VMS use, while Malays had the highest prevalence of FS use. A higher prevalence of dietary supplement consumption was reported among those with tertiary education and monthly income of more than RM3500 (Table 1).

Table 2 presents the adjusted odd ratios with 95 percent confidence interval for socio- demographic and lifestyle characteristic associated with dietary supplement use in MANS 2014. Women, older people, those with higher education level and higher monthly income were positively associated with dietary supplement use. Those living in urban localities were significantly more likely to use FS (OR: $1.34 ; p=0.034)$, but not for VMS. In addition Malays (OR: $2.51 ; p=0.003)$ and Chinese (OR: $2.19 ; p=0.007)$ were significantly more likely to use FS. However, our results showed no significant association between ethnicity and VMS use. This study did not showed any association between dietary supplement use with body mass index and physical activity status.

The specific type of dietary supplement use among Malaysian adults is shown in Table 3. The most commonly used VMS was vitamin C (15.7\%), followed by multivitamin and multimineral (8.9\%) and Calcium (5.8\%). Fish oil was the most common FS consumed $(8.9 \%)$, followed by royal jelly $(6.2 \%)$ and spirulina $(3.3 \%)$. Health reasons, prescribed by doctors and to increase energy level were the main reasons for taking VMS. Meanwhile the main reasons for using FS were for health reasons, to increase energy level and for beauty (Figure 1).

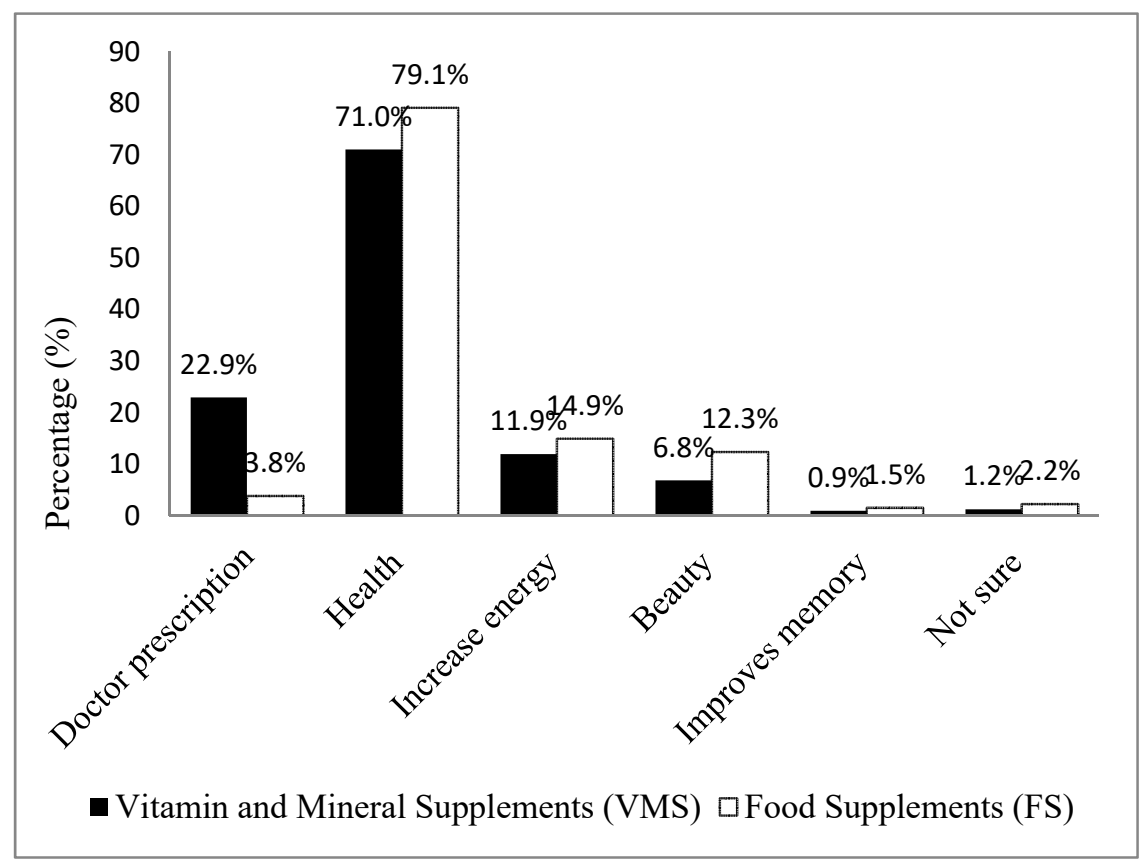

Figure 1. Reasons for using dietary supplements by Malaysian adults 
Table 1. Characteristics of dietary supplements use among Malaysian adults $(\mathrm{N}=3000)$

\begin{tabular}{|c|c|c|c|c|c|c|}
\hline \multirow{2}{*}{ Demographic characteristic } & \multicolumn{3}{|c|}{ Vitamin and mineral supplements (VMS) } & \multicolumn{3}{|c|}{ Food supplements (FS) } \\
\hline & Users (n) & Prevalence (\%) & $95 \% \mathrm{CI}$ & Users (n) & Prevalence (\%) & $95 \% \mathrm{CI}$ \\
\hline Overall & 813 & 28.1 & $5.70-30.50$ & 960 & 34.0 & $31.37-36.77$ \\
\hline \multicolumn{7}{|l|}{ Locality } \\
\hline Urban & 507 & 30.9 & $27.83-34.21$ & 608 & 37.9 & $34.34-41.58$ \\
\hline Rural & 306 & 21.5 & $18.62-24.71$ & 352 & 25.2 & $22.08-28.68$ \\
\hline \multicolumn{7}{|l|}{ Gender } \\
\hline Men & 301 & 24.3 & $21.24-27.65$ & 380 & 30.0 & $26.68-33.60$ \\
\hline Women & 512 & 32.1 & $29.26-35.12$ & 580 & 38.4 & $35.06-41.78$ \\
\hline \multicolumn{7}{|l|}{ Age group (years) } \\
\hline $18-29$ & 205 & 25.0 & $21.56-28.88$ & 212 & 27.4 & $23.25-31.91$ \\
\hline $30-39$ & 253 & 31.8 & $27.55-36.43$ & 282 & 36.2 & $31.96-40.59$ \\
\hline $40-49$ & 207 & 29.7 & $24.84-34.96$ & 251 & 36.2 & $31.43-41.23$ \\
\hline $50-59$ & 148 & 26.3 & $21.81-31.28$ & 215 & 40.3 & $35.07-45.75$ \\
\hline \multicolumn{7}{|l|}{ Ethnicity } \\
\hline Malay & 381 & 26.9 & $23.81-30.18$ & 526 & 38.3 & $34.48-42.27$ \\
\hline Chinese & 174 & 31.8 & $26.36-37.30$ & 205 & 38.1 & $32.55-44.01$ \\
\hline Indian & 43 & 31.2 & $22.41-41.47$ & 34 & 28.6 & $19.98-39.08$ \\
\hline Other Bumiputera & 175 & 26.7 & $22.38-31.49$ & 166 & 23.3 & $18.67-28.58$ \\
\hline Others & 40 & 25.9 & $16.77-37.65$ & 29 & 13.3 & $8.15-20.98$ \\
\hline \multicolumn{7}{|l|}{ Education level } \\
\hline Non formal & 14 & 7.4 & $3.61-14.51$ & 21 & 21.4 & $12.68-33.84$ \\
\hline Primary & 94 & 14.2 & $11.04-18.12$ & 118 & 20.3 & $15.90-25.46$ \\
\hline Secondary & 366 & 25.9 & $22.93-29.25$ & 455 & 31.4 & $28.08-34.84$ \\
\hline Tertiary & 337 & 42.4 & $37.84-47.76$ & 365 & 49.1 & $44.15-54.15$ \\
\hline \multicolumn{7}{|l|}{ Income } \\
\hline Less than RM1500 & 358 & 20.0 & $17.50-22.90$ & 288 & 21.2 & $18.30-24.32$ \\
\hline RM1500-RM3500 & 280 & 33.2 & $29.20-37.40$ & 300 & 35.2 & $31.01-39.60$ \\
\hline More than RM3500 & 167 & 49.3 & $41.94-56.71$ & 359 & 52.5 & $47.54-57.46$ \\
\hline \multicolumn{7}{|l|}{ Body mass index $\left(\mathrm{kg} / \mathrm{m}^{2}\right)$} \\
\hline Underweight $(<18.49)$ & 39 & 21.2 & $14.46-29.84$ & 39 & 23.9 & $16.02-34.05$ \\
\hline Normal (18.5-24.9) & 353 & 28.7 & $25.46-32.19$ & 388 & 33.4 & 29.96-37.09 \\
\hline Overweight (25.0-29.9) & 250 & 28.9 & $24.89-33.19$ & 325 & 34.0 & $29.96-38.31$ \\
\hline Obese $(\geq 30.0)$ & 132 & 25.5 & $20.99-30.61$ & 187 & 40.3 & $34.76-46.07$ \\
\hline \multicolumn{7}{|l|}{ Physical activity } \\
\hline Active & 495 & 28.1 & $25.17-31.19$ & 595 & 35.1 & $31.75-38.52$ \\
\hline Inactive & 300 & 28.2 & $24.69-31.95$ & 346 & 32.6 & $28.53-36.88$ \\
\hline
\end{tabular}


Table 2. Multivariable analyses of the demographic and lifestyle characteristics associated with dietary supplements use by Malaysian adults $(\mathrm{N}=3000)$

\begin{tabular}{|c|c|c|c|c|c|c|c|c|c|}
\hline & & \multicolumn{4}{|c|}{ Vitamin and Mineral supplement (VMS) } & \multicolumn{4}{|c|}{ Food Supplement (FS) } \\
\hline & & $\begin{array}{l}\text { Crude OR }(95 \% \\
\text { CI })\end{array}$ & $P$-Value & $\begin{array}{l}{ }^{a} \text { Adjusted OR }(95 \% \\
\text { CI) }\end{array}$ & $P$-Value & $\begin{array}{c}\text { Crude OR }(95 \% \\
\text { CI) }\end{array}$ & $P$-Value & $\begin{array}{l}{ }^{a} \text { Adjusted OR }(95 \% \\
\text { CI) }\end{array}$ & $P$-Value \\
\hline \multirow[t]{2}{*}{ Locality } & Urban & $1.63(1.29-2.06)$ & $<0.001$ & $1.21(0.94-1.56)$ & 0.14 & $1.81(1.43-2.28)$ & $<0.001$ & $1.34(1.02-1.76)$ & 0.034 \\
\hline & Rural & Ref & & Ref & & Ref & & Ref & \\
\hline \multirow[t]{2}{*}{ Gender } & Women & $1.47(1.21-1.79)$ & $<0.001$ & $1.54(1.24-1.90)$ & $<0.001$ & $1.45(1.20-1.76)$ & $<0.001$ & $1.47(1.22-1.78)$ & $<0.001$ \\
\hline & Men & Ref & & Ref & & Ref & & Ref & \\
\hline \multirow[t]{4}{*}{$\begin{array}{l}\text { Age group } \\
\text { (years) }\end{array}$} & $18-29$ & Ref & & Ref & & Ref & & Ref & \\
\hline & $30-39$ & $1.39(1.06-1.84)$ & $<0.05$ & $1.37(1.01-1.84)$ & $<0.05$ & $1.50(1.14-1.99)$ & 0.004 & $1.41(1.05-1.90)$ & 0.022 \\
\hline & $40-49$ & $1.26(0.92-1.72)$ & 0.14 & $1.40(1.00-1.96)$ & $<0.05$ & $1.51(1.14-1.99)$ & 0.004 & $1.54(1.12-2.12)$ & 0.008 \\
\hline & $50-59$ & $1.06(0.80-1.42)$ & 0.66 & $1.45(1.01-2.08)$ & $<0.05$ & $1.79(1.32-2.42)$ & $<0.001$ & $2.36(1.68-3.32)$ & $<0.001$ \\
\hline \multirow[t]{6}{*}{ Ethnicity } & Malay & $1.05(0.53-1.87$ & 0.86 & & & $4.04(2.28-7.16)$ & $<0.001$ & $2.51(1.38-4.58)$ & 0.003 \\
\hline & Chinese & $1.33(0.76-2.35)$ & 0.32 & & & $4.01(2.26-7.11)$ & $<0.001$ & $2.19(1.24-3.85)$ & 0.007 \\
\hline & Indian & $1.29(0.60-2.80)$ & 0.51 & & & $2.61(1.34-5.07)$ & $<.0 .001$ & $1.61(0.77-3.32)$ & 0.20 \\
\hline & $\begin{array}{l}\text { Others } \\
\text { Bumiputera }\end{array}$ & $1.04(0.57-1.89)$ & 0.89 & & & $1.98(1.09-3.59)$ & 0.026 & $1.76(0.96-3.25)$ & 0.07 \\
\hline & Others & Ref & & & & Ref & & Ref & \\
\hline & Non formal & Ref & & Ref & & Ref & & Ref & \\
\hline \multirow{4}{*}{$\begin{array}{l}\text { Education } \\
\text { level }\end{array}$} & Primary & $2.08(0.91-4.74)$ & 0.08 & $2.03(0.88-4.68)$ & 0.10 & $0.93(0.48 \backslash-1.80)$ & 0.834 & $0.83(0.43-1.59)$ & 0.57 \\
\hline & Secondary & $4.40(2.02-9.60)$ & $<0.001$ & $4.13(1.83-9.32)$ & $<0.001$ & $1.68(1.89-3.17)$ & 0.11 & $1.38(0.72-2.54)$ & 0.34 \\
\hline & Tertiary & $9.36(4.27-20.53)$ & $<0.001$ & $7.30(3.14-16.99)$ & $<0.001$ & $3.55(1.84-6.84)$ & $<0.001$ & $2.38(1.18-4.80)$ & $<0.001$ \\
\hline & $\begin{array}{l}\text { Less than } \\
\text { RM1500 }\end{array}$ & Ref & & Ref & & Ref & & Ref & \\
\hline \multirow[t]{3}{*}{ Income } & $\begin{array}{l}\text { RM1500-RM } \\
3500\end{array}$ & $1.98(1.54-2.55)$ & $<0.001$ & $1.21(0.88-1.66)$ & $<0.001$ & $2.02(1.58-2.59)$ & $<0.001$ & $1.68(1.31-2.16)$ & $<0.001$ \\
\hline & $\begin{array}{l}\text { More than } \\
\text { RM3500 }\end{array}$ & $3.89(2.75-5.50)$ & $<0.001$ & $2.12(1.49-3.00)$ & 0.24 & $4.12(3.23-5.27)$ & $<0.001$ & $2.61(1.95-3.49)$ & $<0.001$ \\
\hline & $\begin{array}{l}\text { Underweight } \\
(<18.49)\end{array}$ & $0.67(0.42-1.06)$ & 0.09 & $0.80(0.47-1.35)$ & 0.39 & $0.63(0.37-1.06)$ & 0.08 & $0.75(0.41-1.37)$ & 0.35 \\
\hline \multirow{3}{*}{$\begin{array}{l}\text { Body Mass } \\
\text { Index } \\
\left(\mathrm{kg} / \mathrm{m}^{2}\right)\end{array}$} & $\begin{array}{l}\text { Normal } \\
(18.5-24.9)\end{array}$ & Ref & & Ref & & Ref & & Ref & \\
\hline & $\begin{array}{l}\text { Overweight } \\
(25.0-29.9)\end{array}$ & $1.08(0.79-1.28)$ & 0.95 & $0.93(0.72-1.19)$ & 0.54 & $1.03(0.82-1.28)$ & 0.820 & $0.84(0.67-1.05)$ & 0.12 \\
\hline & $\begin{array}{l}\text { Obese } \quad(\geq \\
30.0)\end{array}$ & $0.85(0.63-1.15)$ & 0.29 & $0.74(0.54-1.00)$ & 0.51 & $1.34(1.04-1.74)$ & 0.026 & $1.12(0.86-1.48)$ & 0.39 \\
\hline \multirow[t]{2}{*}{$\begin{array}{l}\text { Physical } \\
\text { activity }\end{array}$} & Active & $0.99(0.80-1.25)$ & 0.97 & & & $1.12(0.89-1.41)$ & 0.35 & & \\
\hline & Inactive & Ref & & & & Ref & & & \\
\hline
\end{tabular}

\footnotetext{
${ }^{\mathrm{a}}$ adjusted for all other variables.
}

Ref; references. 
Table 3. Specific types of dietary supplement use by Malaysian adults

\begin{tabular}{|c|c|c|c|}
\hline Type of Supplements & Prevalence (\%) & $95 \% \mathrm{CI}$ & Estimated population (N) \\
\hline \multicolumn{4}{|l|}{ Vitamin and Mineral Supplements (VMS) } \\
\hline Vitamin C & 15.68 & $13.92-17.61$ & $3,073,050$ \\
\hline Multivitamin \& multimineral & 8.87 & $7.49-10.47$ & $1,738,152$ \\
\hline Calcium & 5.84 & $4.48-7.04$ & $1,144,848$ \\
\hline Vitamin B Complex & 5.62 & $4.70-6.71$ & $1,102,200$ \\
\hline Folic Acid & 2.70 & $1.99-3.64$ & 528,814 \\
\hline vitamin $\mathrm{E}$ & 2.62 & $1.96-3.49$ & 513,265 \\
\hline Iron & 2.06 & $1.57-2.69$ & 403,487 \\
\hline Zinc & 1.32 & $0.86-2.03$ & 258,771 \\
\hline Vitamin A & 0.76 & $0.39-1.49$ & 150,814 \\
\hline Vitamin B12 & 0.78 & $0.50-1.21$ & 152,087 \\
\hline \multicolumn{4}{|l|}{ Food Supplements (FS) } \\
\hline Fish oil & 8.92 & $7.48-10.58$ & $1,749,591$ \\
\hline Royal Jelly & 6.15 & $4.88-7.71$ & $1,206,149$ \\
\hline Spirulina & 3.34 & $2.67-4.30$ & 665,569 \\
\hline Collagen & 2.92 & $2.26-3.77$ & 573,746 \\
\hline Traditional Herbs & 2.76 & $2.05-3.70$ & 542,319 \\
\hline Essence of chicken & 2.66 & $1.98-3.54$ & 521,140 \\
\hline Health powder (exclude slimming product) & 2.57 & $1.85-3.43$ & 495,881 \\
\hline Evening Primrose Oil & 2.22 & $1.63-3.02$ & 436,794 \\
\hline Slimming Products & 1.72 & $1.05-2.78$ & 336,689 \\
\hline Bird's nest stock & 1.61 & $1.11-2.32$ & 316,596 \\
\hline Sea Cucumber Products & 1.13 & $0.73-1.75$ & 223,356 \\
\hline Garlic pil & 0.73 & $0.40-1.34$ & 144,474 \\
\hline Haruan fish stock & 0.68 & $0.43-1.10$ & 134,346 \\
\hline Berry Essence & 0.67 & $0.38-1.18$ & 132,516 \\
\hline Gingko Biloba & 0.64 & $0.37-1.11$ & 127,020 \\
\hline Prune Essence & 0.27 & $0.12-0.63$ & 54,220 \\
\hline Mangosteen Extract & 0.22 & $0.11-0.47$ & 43,247 \\
\hline
\end{tabular}

\section{Discussion}

In this population-based study, we studied the prevalence and characteristics of the dietary supplement among the Malaysian adults. The current study revealed that about $28 \%$ and $34 \%$ of the Malaysian adults consumed VMS and FS supplements respectively, which were slightly increased than the previous Malaysian Adults Nutrition Survey in 2003. The prevalence of VMS and FS used among Malaysian adults reported in previous MANS 2003 were $23.9 \%$ and $24.8 \%$, respectively (Ministry of Health Malaysia, 2008). Another studies also had examined dietary supplement used in Malaysia; however, due to limitation in sample representative comprehensiveness, the findings could not be generalized to the Malaysian adults. A study among 105 university students in Kuala Lumpur found that $43.0 \%$ took vitamin and mineral supplements (Al-Naggar \& Chen, 2011). Ghazali et al. (2006) reported that $66.8 \%$ of 247 residents in urban areas were regular users of dietary supplements (Ghazali et al., 2006). The wide and easy availability of dietary supplements over the counter at pharmacies, convenience shops, Chinese medical hall and even via online shopping as well as belief of the users that supplements might provide great health benefits could be the plausible reasons for the increment of the dietary supplements use among Malaysians. In addition, 
regulation or health policy on the use of dietary supplements in Malaysia is still not implemented. Currently under the National Pharmaceutical Control Bureau, Malaysia (NPCB), dietary supplement need to registered and licensed to ensure the quality, safety and efficacy of supplements for the local market (National Pharmaceutical Control Bureau Ministry of Health Malaysia, 2011).

The prevalence of dietary supplements usage among Malaysian adult was considerably lower than findings from other countries. Nearly half of the adult population in the USA and European countries reported consuming dietary supplements (Bailey et al., 2011; Gahche et al., 2011; Skeie et al., 2009). The reasons for the high prevalence of regular dietary supplement used among adults in the US over the 5 years were due to maintain and promote personal health as well as part of their healthy habits (Bailey et al., 2013; Dickinson et al., 2014). In South Korea, between 2005 and 2006 about 62\% of adults had taken dietary supplements (Ock et al., 2010). Another study in France revealed that during the past 12 months, about $41 \%$ of the adults consume at least one dietary supplement (Pouchieu et al., 2013). However, the lowest prevalence of dietary supplement used was reported among the Mediterranean population at 9.3\% (Rovira et al., 2013).

Consistent with other studies; this study found that dietary supplements used was significantly higher in women than in men (Pouchieu et al., 2013; Rovira et al., 2013; Xiaoyan et al., 2009). This might be due a greater awareness among women to maintain healthy or wellness (Dickinson \& MacKay, 2014). Various studies had shown that respondents in the older age group were more likely to use dietary supplements (Dickinson \& MacKay, 2014; Pouchieu et al., 2013). The result of this study confirmed these findings in the Malaysian settings. A study in the USA found that older people had been associated with greater likelihood of consuming multivitamin-multimineral supplements (Rock, 2007). However, a study conducted in Italy found negative association between age and consumption of food supplements (Giammarioli et al., 2013). One might hypothesize that the existence of chronic diseases or health condition would make older people to be more motivated to use dietary supplement as a complement to disease treatments (Denison et al., 2012).

In agreement with other studies, those with higher education level and higher economic background reported to consume more dietary supplements (Pouchieu et al., 2013; Rovira et al., 2013). Possible explanations might be that adults with better educational level usually have better financial status and they are more likely to be better informed about the health benefit of consuming dietary supplements. Subramanian et al. (2010) reported that higher education level had a positive association with greater health awareness (Subramanian et al., 2010). Thus, more educated respondents with a higher income would enable them to buy those supplements. Our results found no statistical significance among urban residency and VMS but showed positive association for FS usage. Ock et al. (2010) found that residents in metropolitan areas were more likely to use dietary supplement (Ock et al., 2010). In Italy, the use of dietary supplements was also significantly higher in the Northeast of Italy and in large towns compared to small towns (Giammarioli et al., 2013).

Our study found no association in body weight status and physical activity with the dietary supplement use. These findings were in contrast with previous study whereby those who had lower body mass index and physically active were more likely to use dietary supplements (P Marques-Vidal et al., 2009; Pouchieu et al., 2013). A review by Dickinson and MacKay concluded that dietary supplements user were more likely than non-users to implement a healthy habits that include exercise regularly and maintaining a healthy body weight (Dickinson \& MacKay, 2014).

In our study, the most common VMS taken by Malaysian adults was Vitamin $\mathrm{C}$, followed by multivitamin/multi-mineral. Our results concurred with studies in France and United States which found that Vitamin C was one of the most regularly used supplement (Bailey et al., 2011; Pouchieu et al., 2013). Vitamin C has been one of the most frequently used supplements because of the role as potent antioxidant in cancer and CVD prevention (Grosso et al., 2013). Meanwhile, the most common FS supplement consumed by Malaysian adults was fish oil and royal jelly. Oil based supplements (e.g. cod liver oil) was popular in several European countries (Skeie et al., 2009). This result probably may due to the potential benefit of omega-3 fatty acid in fish oil to prevent and treatment of CVD (Weitz et al., 2010). The main reasons Malaysian adults took supplements were due to health reasons, on doctor's prescription, to increase energy and for beauty. The NHANES (2007-2010) reported that to improve or maintain overall health, for bone health and to supplement the diet were the most common reasons among US civilians for using dietary supplements (Bailey et al., 2011).

There are several limitations and strength of the present study. Firstly, the respondents may have different understanding and interpretation due to the definitions of the VMS and FS in this study; this might result in different understandings of dietary supplements among respondents. Secondly, the respondents may be under-or over reporting their dietary supplements usage as this study is self-reported. Finally, despite these limitations, the 
strength of this study included a large representative sample size with high a response rate. Therefore, the findings could represent Malaysian adults on the use of dietary supplements and could provide important information for surveillance purposes.

In summary, the Malaysian Adults Nutrition Survey 2014 found that about 28\% and 34\% of Malaysian adults reported to consume VMS and FS supplements respectively. Women, older people, those with higher education level and higher monthly income were associated with dietary supplement use. Further studies to examine the role of dietary supplement use in relation to nutrients adequacy, overconsumption and health are recommended.

\section{Acknowledgments}

The authors would like to thank the study respondents for their willingness to participate in this study. Our special appreciation goes to all staff and investigators for their valuable contribution in this study.

\section{Competing Interests Statement}

The authors declare that there are no competing or potential conflicts of interest.

\section{References}

Al-Naggar, R. A., \& Chen, R. (2011). Prevalence of vitamin-mineral supplements use and associated factors among young Malaysians. Asian Pac J Cancer Prev, 12, 1023-1029.

Bailey, R. L., Gahche, J. J., Lentino, C. V., Dwyer, J. T., Engel, J. S., Thomas, P. R., ... Picciano, M. F. (2011). Dietary supplement use in the United States, 2003-2006. $J$ Nutr, 141, 261-6. https://doi.org/10.3945/jn.110.133025

Bailey, R. L., Gahche, J. J., Miller, P. E., Thomas, P. R., \& Dwyer, J. T. (2013). Why US adults use dietary supplements. JAMA Intern Med, 173, 355-61. https://doi.org/10.1001/jamainternmed.2013.2299

Comerford, K. B. (2013). Recent Developments in Multivitamin/Mineral Research. Adv Nutr, 4, 644-656. https://doi.org/10.3945/an.113.004523

Denison, H., Jameson, K., Syddall, H., Dennison, E., Cooper, C., Sayer, A. A., \& Robinson, S. (2012). Patterns of dietary supplement use among older men and women in the UK: findings from the Hertfordshire Cohort Study. J Nutr Health Aging, 16, 307-311. https://doi.org/10.1007/s12603-012-0016-1

Dickinson, A., Blatman, J., El-Dash, N., \& Franco, J. C. (2014). Consumer usage and reasons for using dietary supplements: report of a series of surveys. $J$ Am Coll Nutr, 33, 176-182. https://doi.org/10.1080/07315724.2013.875423

Dickinson, A., Bonci, L., Boyon, N., \& Franco, J. C. (2012). Dietitians use and recommend dietary supplements: report of a survey. Nutr J, 11, 14. https://doi.org/10.1186/1475-2891-11-14

Dickinson, A., \& MacKay, D. (2014). Health habits and other characteristics of dietary supplement users: a review. Nutr J, 13, 14. https://doi.org/10.1186/1475-2891-13-14

Gahche, J., Bailey, R., Burt, V., Hughes, J., Yetley, E., Dwyer, J., ... Sempos, C. (2011). Dietary supplement use among US adults has increased since NHANES III (1988-1994). NCHS Data Brief, 1-8.

Ghazali, E., Mutum, D., \& Lee, L. (2006). Dietary supplement users vs nonusers In Malaysia: profile comparisons for marketing purposes. AGBA 3rd World Congress, Advances in Global Business Research, Kuala Lumpur, Citeseer, 43-54.

Giammarioli, S., Boniglia, C., Carratu, B., Ciarrocchi, M., Chiarotti, F., Mosca, M., \& Sanzini, E. (2013). Use of food supplements and determinants of usage in a sample Italian adult population. Public Health Nutr, 16, 1768-1781. https://doi.org/10.1017/S1368980012004314

Goston, J. L., \& Correia, M. I. T. D. (2010). Intake of nutritional supplements among people exercising in gyms and influencing factors. Nutrition, 26, 604-611. https://doi.org/10.1016/j.nut.2009.06.021

Grosso, G., Bei, R., Mistretta, A., Marventano, S., Calabrese, G., Masuelli, L., ... Gazzolo, D. (2013). Effects of vitamin C on health: a review of evidence. Front Biosci (Landmark Ed), 18, 1017-1029. https://doi.org/10.2741/4160

Guallar, E., Stranges, S., Mulrow, C., Appel, L. J., \& Miller, E. R. (2013). Enough is enough: stop wasting money on vitamin and mineral supplements. Ann Intern Med, 159, 850-851. https://doi.org/10.7326/0003-4819-159-12-201312170-00011

Institute for Public Health (IPH). (2014). National Health and Morbidity Survey 2014: Malaysian Adults Nutrition 
Survey (MANS) (Vol 1: Methodology and General Findings). Kuala Lumpur, Malaysia.

National Pharmaceutical Control Bureau Ministry of Health Malaysia. (2011). Guidance of classification [Accessed Accessed Februari 23, 2017. www.bpfk.gov.my].

Ock, S.-M., Hwang, S.-S., Lee, J.-S., Song, C.-H., \& Ock, C.-M. (2010). Dietary supplement use by South Korean adults: Data from the national complementary and alternative medicine use survey (NCAMUS) in 2006. Nutr Res Pract, 4, 69. https://doi.org/10.4162/nrp.2010.4.1.69

Marques-Vidal, P., Pecoud, A., Hayoz, D., Paccaud, F., Mooser, V., Waeber, G., \& Vollenweider, P. (2009). Prevalence and characteristics of vitamin or dietary supplement users in Lausanne, Switzerland: the CoLaus study. European journal of clinical nutrition, 63(2), 273-281. https://doi.org/10.1038/sj.ejcn.1602932

Pouchieu, C., Andreeva, V. A., Péneau, S., Kesse-Guyot, E., Lassale, C., Hercberg, S., \& Touvier, M. (2013). Sociodemographic, lifestyle and dietary correlates of dietary supplement use in a large sample of French adults: results from the NutriNet-Sante cohort study. British Journal of Nutrition, 110(8), 1480-1491. https://doi.org/10.1017/S0007114513000615

Rock, C. L. (2007). Multivitamin-multimineral supplements: who uses them?. The American journal of clinical nutrition, 85(1), 277S-279S. https://doi.org/10.1093/ajcn/85.1.277S

Rovira, M. A., Grau, M., Castañer, O., Covas, M. I., Schröder, H., \& REGICOR Investigators. (2013). Dietary supplement use and health-related behaviors in a Mediterranean population. Journal of nutrition education and behavior, 45(5), 386-391. https://doi.org/10.1016/j.jneb.2012.03.007

Skeie, G., Braaten, T., Hjartåker, A., Lentjes, M., Amiano, P., Jakszyn, P., ... \& Avloniti, K. (2009). Use of dietary supplements in the European Prospective Investigation into Cancer and Nutrition calibration study. European journal of clinical nutrition, 63(S4), S226. https://doi.org/10.1038/ejen.2009.83

Subramanian, S. V., Huijts, T., \& Avendano, M. (2010). Self-reported health assessments in the 2002 World Health Survey: how do they correlate with education?. Bulletin of the World Health Organization, 88, 131-138. https://doi.org/10.2471/BLT.09.067058

Weitz, D., Weintraub, H., Fisher, E., \& Schwartzbard, A. Z. (2010). Fish oil for the treatment of cardiovascular disease. Cardiology in review, 18(5), 258. https://doi.org/10.1097/CRD.0b013e3181ea0de0

World Health Organisation [WHO]. (2000). Obesity: Preventing and managing the global epidemic. WHO Obesity Technical Report Series No. 894. World Health Organization, Geneva.

World Health Organization [WHO]. (2004). Global Physical Activity Questionnaire (GPAQ) and analysis guide. Geneva.

Wu, C.-H., Wang, C.-C., \& Kennedy, J. (2011). Changes in herb and dietary supplement use in the US adult population: a comparison of the 2002 and 2007 National Health Interview Surveys. Clin Ther, 33, 1749-1758. https://doi.org/10.1016/j.clinthera.2011.09.024

Xiaoyan, G., Noreen, W., Stefan, K., Gian, J., \& Paul, J. V. (2009). Use of Vitamin and Mineral Supplements among Canadian Adults. Can J Public Health, 100, 357-360.

\section{Copyrights}

Copyright for this article is retained by the author(s), with first publication rights granted to the journal.

This is an open-access article distributed under the terms and conditions of the Creative Commons Attribution license (http://creativecommons.org/licenses/by/4.0/). 